\title{
COMPLICATIONS OF CHRONIC SUPPURATIVE OTITIS MEDIA
}

\author{
1. Town Teaching Hospital \\ 2. Kohat Medical College \\ 3. Khyber Teaching Hospital \\ 4. Naseer Teaching Hospital
}

Arifullah ${ }^{1}$, Syed Zafar Hasan², Islam Gul ${ }^{3}$, Waqar-Ud-Din ${ }^{4}$, Aftab Ahmed $^{4}$

\section{OBJECTIVE}

The aim of the study was to find the complications of chronic suppurative otitis media.

MATERIAL AND METHODS

The study was descriptive study conducted from 1st January 2008 to 31 December 2010 (3 years duration) at ENT department Khyber Teaching Hospital Peshawar. Total 250 patients of all age having complications due to chronic suppurative otitis media enrolled from admitted patients in ENT department Khyber Teaching Hospital Peshawar were included in the study, using convenience (non-probability) sampling.

\section{RESULTS}

In total of 250 patients, all (100\%) were having history of discharging ear, decreased hearing 250 (100\%), earache in 75 (30\%), fever in 31(12.4\%), headache in $28(11.2 \%)$, nausea and vomiting in $23(9.2 \%)$ patients. The extracranial complications were found in 204/250 (81.6\%) patients with mastoiditis being the most common in 155/204 (75.98\%) patients followed by sensory reural hearing loss, post auricular abscess, facial paralysis, petrositis, labynthitis, Bezold's abscess and cetili's abscess in 7.84\%, 6.37\%, 5.88\%, 1.7\%, 0.98\%, $0.98 \%$ and $0.49 \%$ patients respectively. While the intracranial complications were found in $46 / 250$ (18.4\%) patients with meningitis being the most common in $28 / 46$ (60.9\%) followed by brain abscess in $26 \%$, lateral sinus thrombosis in $8.7 \%$ and otitic hydrocephalus in $4.4 \%$ patients.

\section{CONCLUSION}

Early detection and treatment of complications as a result of chronic suppurative otitis is vital to prevent morbidity and mortality.

\section{KEY WORD}

Chronic suppurative otitis media, intracranial complications, extracranial complications

\section{INTRUDUCTION}

Chronic suppurative otitis media is a long-standing infection (more than 12 weeks) of a part or whole of the middle ear cleft characterized by ear discharge and permanent tympanic membrane perforation ${ }^{1}$.Complications of suppurative otitis media occur when infection spreads

Correspondence:

Dr. Arifullah

Town Teaching Hospital

Contact: 0302-5563597

Email: drmrf@hotmail.com

https://doi.org/10.37762/jgmds.3-01.46 outside the confines of the bony walls of middle ear and mastoid spaces (middle ear cleft). Various routes for spread of infections include pathological bony defects (e.g. demineralization, bony erosion and granulation tissue), infected thrombus in veins (e.g. lateral sinus associated with cerebellar abscesses and superior

petrosal sinus with temporal lobe abscesses), normal anatomical pathways (e.g. oval round windows, cochlear and vestibular aqueducts), anatomical dehiscence (e.g. dehiscence over Jugular bulb, middle cranial fossa dura and facial nerve), non-anatomical bony defects (e.g. trauma and surgery/iatrogenic) and neoplasms. Once into the brain tissue infection can spread via Periarteriolar spaces of Virchow-Robin. ${ }^{2}$ The complications of otitis media have been divided into intracranial and intratemporal (extracranial) complications ${ }^{3}$. The extracranial complications of chronic suppurative otitis media include mastoid abscess, discharging sinuses, purulent 
labyrinthitis, Bezold's abscess, facial nerve paralysis and zygomatic abscess ${ }^{4}$. Cervical osteomyelitis may develop as a rare complication and present as a cause of severe neck pain in patients with otitis media ${ }^{7}$. Among the intracranial complications the most common is meningitis followed by brain abscess, epidural abscess, sigmoid sinus thrombosis, subdural empyema, perisinus abscess and transverse and cavernous sinus thrombosis ${ }^{6}$. Clinical features of intracranial complications include fever, lethargy, focal neurologic signs (e.g. ataxia, oculomotor deficits and seizure), papilledema, meningismus, altered mental status and severe headache. Clinical features of extracranial complications include fever, post auricular oedema or erythema, facial nerve paresis or paralysis, fetid otorrhea, retro-orbital pain on the side of the infected ear, vertigo, spontaneous nystagmus associated with sensorineural hearing loss and an infected ear. ${ }^{7}$ The complications and the morbidity of complications in children are more extensive than in adult group ${ }^{8}$. Symptoms can be no characteristics and must be asked for a CT in case of doubt; CT is of the first rank in diagnosis ${ }^{9}$.

The management of complications includes hospital admission, medical treatment and surgery. Medical treatment includes antibiotics (the combinations of third- or fourth-generation cephalosporin with chloramphenicol, vancomycin, metronidazole or aminoglycosides) to cover infection, vestibular suppressants for vestibular symptoms as well as anticonvulsant for seizures and anticoagulant (controversial) for thrombosis ${ }^{10}$. Surgical options include mastoid exploration to eradicate primary source of infection while the treatment of otogenic brain abscess initially involves aspiration or excision of the abscess through a temporal or sub-occipital route depending on its location followed by a mastoid exploration by the ENT surgeon to eradicate the primary source of infection ${ }^{11}$.

\section{MATERIAL AND METHODS}

It was a cross sectional descriptive study of three years duration from $1^{\text {st }}$ Jan 2008 to $31^{\text {st }}$ Dec 2010, conducting in the ENT department of Khyber teaching hospital, Peshawar. Sample size was 250 patients, having complications (intracranial and extracranial) secondary to chronic suppurative otitis. All patients of either gender presenting with discharging ear for more than 6-12 weeks and perforated tympanic membrane diagnosed clinically as chronic suppurative otitis media with its complications of any age were included in the study. And excluding those patients with traumatic perforation of tympanic membrane and other causes of brain abscess, meningitis and facial nerve palsy

\section{METHODOLOGY}

The study was conducted after getting approval from hospital ethical and research committee. The patients meeting the inclusion criteria were included in the study through OPD/ER department. The diagnosis of complications of chronic suppurative otitis media was made by detail history taking, ontological and neurological findings followed by CT scan and CSF laboratory findings. The complications were divided into intracranial and extracranial (intratemporal), and percentage was calculated accordingly for all gender and ages. All the above-mentioned information including name, age, gender, address and telephone numbers were recorded on a predesigned proforma. A strict inclusion criterion was followed to control confounders and bias in the study results. Data was entered into SPSS version 16. Descriptive statistics were used to calculate mean and standard deviation for age and duration of discharging ear with perforated tympanic membrane and otogenic brain abscess. Frequencies (\%) were calculated for gender, presenting symptoms, examination findings and CT scan findings. 


\section{RESULTS}

In total of 250 patients, $108(43.2 \%)$ were $1-15$ years, 64 (25.6\%) were $16-30$ years, 78 $(31.2 \%)$ more than 30 years. Out of 250 patients $130(52 \%)$ were male and $120(48 \%)$ were female as shown in figure \#1. In total of 250 patients all (100\%) were having history of discharging ears, decreased hearing in 250 (100\%), earache in $75(30 \%)$, fever in 31(12.4\%), headache in 28 $(11.2 \%)$, nausea and vomiting in $23(9.2 \%)$, altered conscious level in $25(10 \%)$, neck rigidity in 13 $(5.2 \%)$, focal neurological deficit in $5(2 \%)$ and seizure $5(2 \%)$ as shown in table \#2. All the patients suspected of any extracranial and intracranial complications were further investigated by doing temporal region CT scan. In comparison, the extracranial complications in 204/250 (81.6\%) were relatively more common as compared to the intracranial complications in $46 / 250$ (18.4\%) as shown in figure \# 1.

In total of 204 extracranial complications, the most common one was mastoiditis in 155/204 (75.98\%) patients followed by sensory reural hearing loss, post auricular abscess, facial paralysis, petrositis, labynthitis, Bezold's abscess and cetili's abscess in 16/204 (7.84\%), 13/204 (6.37\%), $12 / 204$ (5.88\%), 3/204 (1.7\%), 2/204 (0.98\%), 2/204 (0.98\%) and 1/204 (0.49\%) patients respectively as shown in table 3 . Among the 46 intracranial complications the most common was meningitis in $28 / 46(60.9 \%)$ followed by brain abscess in $12 / 46(26 \%)$, lateral sinus thrombosis in $4 / 46(8.7 \%)$ and otitic hydrocephalus in $2 / 46(4.4 \%)$ patients as shown in table 4 . The overall complications are shown in figure 2.

Table 1: Demographic features

\begin{tabular}{|ll|l|l|}
\hline Sex and age of patients & $\begin{array}{l}\text { Number } \\
\text { patients }\end{array}$ & of & Percentages \\
\hline Gender & Male & $130 / 250$ & $52 \%$ \\
& Female & $120 / 250$ & $48 \%$ \\
\hline Age of patients & $1-15$ years & $108 / 250$ & $43.2 \%$ \\
& $16-30$ years & $64 / 250$ & $25.6 \%$ \\
& More than 30 years & $78 / 250$ & $31.2 \%$ \\
\hline
\end{tabular}

Table 2: Clinical features

\begin{tabular}{|l|l|l|}
\hline Features & Number of patients & Percentage \\
\hline Ear discharge & $250 / 250$ & $100 \%$ \\
\hline Decreased hearing & $250 / 250$ & $100 \%$ \\
\hline Earache & $75 / 250$ & $30 \%$ \\
\hline Fever & $31 / 250$ & $12.4 \%$ \\
\hline Headache & $28 / 250$ & $11.2 \%$ \\
\hline Nausea/vomiting & $23 / 250$ & $9.2 \%$ \\
\hline Altered conscious level & $25 / 250$ & $10 \%$ \\
\hline Neck rigidity & $13 / 250$ & $5.2 \%$ \\
\hline Focal defect & $5 / 250$ & $2 \%$ \\
\hline Seizure & 5,250 & $2 \%$ \\
\hline
\end{tabular}


Figure \# 1: Comparison of extra cranial and intracranial complications

Extracranial 204 and intracranial 46

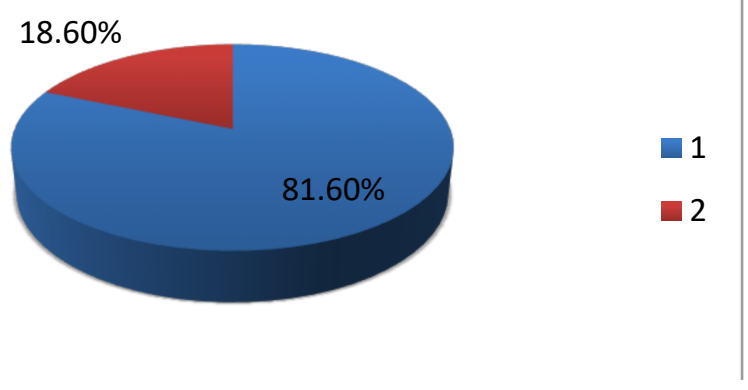

Table 3: Frequency of Extracranial Complications

\begin{tabular}{|l|c|c|}
\hline \multicolumn{1}{|c|}{ Extracranial complications } & Number of patients/204 & Percentage \\
\hline Mastoiditis & $155 / 204$ & $75.98 \%$ \\
\hline Sensory Neural Hearing Loss & $16 / 204$ & $7.84 \%$ \\
\hline Post-Auricular Abscess & $13 / 204$ & $6.37 \%$ \\
\hline Facial Paralysis & $12 / 204$ & $5.88 \%$ \\
\hline Petrositis & $3 / 204$ & $1.47 \%$ \\
\hline Labrynthitis & $2 / 204$ & $0.98 \%$ \\
\hline Bezold's abscess & $2 / 204$ & $0.98 \%$ \\
\hline Citelli's abscess & $1 / 204$ & $0.49 \%$ \\
\hline
\end{tabular}

Table 4: Frequency of Intracranial Complication

\begin{tabular}{|l|c|c|}
\hline Intracranial Complication & Number of Patients/46 & Percentage \\
\hline Meningitis & $28 / 46$ & $60.9 \%$ \\
\hline Brain Abscess & $12 / 46$ & $26 \%$ \\
\hline Lateral Sinus Thrombosis & $4 / 46$ & $8.7 \%$ \\
\hline Otitic Hydrocephalus & $2 / 46$ & $4.4 \%$ \\
\hline
\end{tabular}

Figure \# 2: Relative frequency of complications in CSOM

$1=$ mastoiditis, $2=$ meningitis, $3=\mathrm{SNHL}$, $4=$ postaural abscess, $5=$ facial paralysis, $6=$ brain abscess,

7= lateral sinus thrombosis, 8=petrositis, 9=labyrinthitis, 10=bezold's abscess, 11=otitic

hydrocephalus, $12=$ citelli's abscess

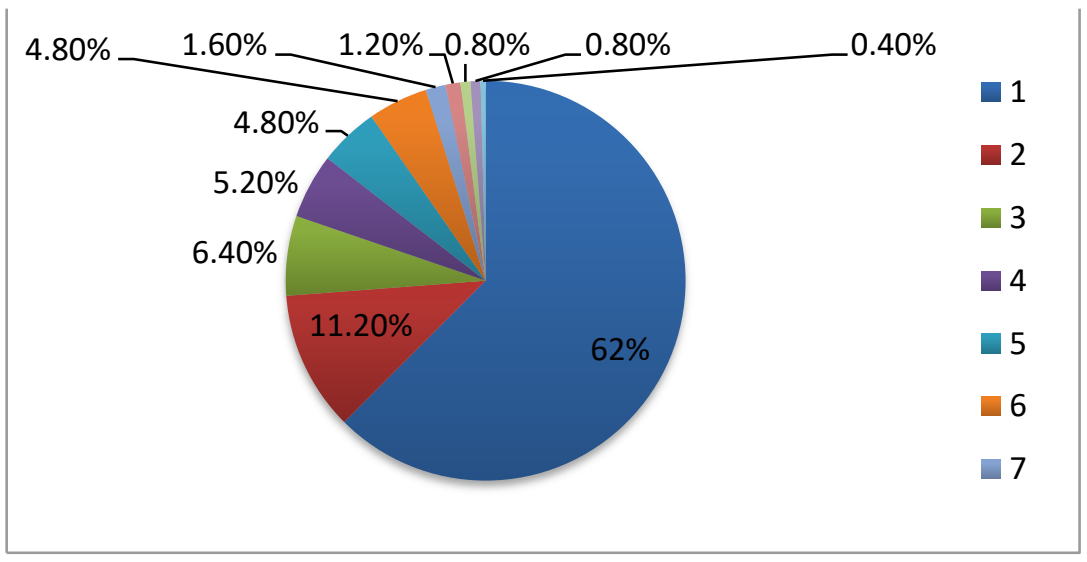




\section{DISCUSSION}

Chronic suppurative otitis media is one the major middle ear infectious disease worldwide mostly occurs in children of low socioeconomic group ${ }^{12}$. In a study by Dubey SP et all majority of patients having chronic suppurative otitis media with complications were under 18 years of age, with male twice that of female ${ }^{13}$. In our study majority of the patients 108 (43.2\%) were 1-15 years, with $52 \%$ male. Chronic suppurative otitis media may cause serious intracranial and extracranial complication with high mortality and morbidity. In Finland the extracranial complications were in $97 \%$ while intracranial complications were $3 \%{ }^{5}$. In Egypt, the ratio of extracranial to intracranial complications was nearly $1: 1^{6}$. In our study the extracranial complications in 204 $(81.6 \%)$ were relatively more common as compared to the intracranial complications in 46 (18.4\%). In New Guinea, among the extracranial complications, 37\% were mastoid abscess, $24 \%$ postauricular fistula and $14 \%$ facial palsy ${ }^{14}$. In China, facial paralysis was the commonest extracranial complication followed by suppurative labyrinthitis and periauricular abscess $^{15}$. In our study, the most common extracranial complication was mastoiditis $62 \%$, followed by sensorineural hearing loss $6.5 \%$, the post auricular abscess $5.6 \%$ and facial nerve paralysis $5.2 \%$ while other like petrositis, labyrinthitis, Bezold's abscess and Citelli's abscess were relatively uncommon as $1.2 \%, 0.8 \%, 0.8 \%$ and $0.4 \%$ respectively.

In Turkey, the perisinus abscess was the most common intracranial abscess, followed by temporal lobe abscess, epidural abscess, cerebellar abscess and subdural empyema ${ }^{16}$. In Brazil otogenic brain abscess was most common followed by meningitis, lateral sinus thrombosis, subdural empyemas and epidural empyema ${ }^{17}$. In our study among the intracranial complications the most common was meningitis $11 \%$, followed by brain abscess $4.8 \%$ and less common as lateral sinus thrombosis and otitic hydrocephalus as $1.2 \%$ and $0.4 \%$ respectively. Complication should be considered in any patient with chronic suppurative otitis media who is generally unwell and in particularly with symptoms such as pyrexia and headache. Early and effective management of complication is important. CT scanning is a reliable diagnostic tool for diagnosis of complications of chronic suppurative otitis media ${ }^{18}$. In our study we did CT scan in all cases with suspected complications. Surgeries were the main mode of treatment for majority of these conditions?.In our study all such patients with complications due to chronic suppurative otitis media were treated first by medically and then surgically offering mastoid exploration to eradicate the primary cause. Patients with brain abscess were sent to neurosurgery department for aspiration of abscess followed by mastoid surgeries in ENT unit after full recovery.

\section{CONCLUSION}

Chronic suppurative otitis media causes extracranial/intracranial complications.

The mortality and morbidity due to these complications are preventable if early detected and treated.

Complications should always be considered in patients who have chronic suppurative otitis media presenting with headache, focal neurological deficit, seizures, nausea and vomiting.

CT scan is the investigation of choice for detection of complications in chronic suppurative otitis media. 


\section{RECOMMENDATION}

Early detection and treatment of complications due to chronic suppurative otitis media are important in preventing morbidity and mortality.

\section{REFERENCES}

1. Verhoeff $M$, van der Veen, $E L$, Rovers $M M$ et.al. Chronic suppurative otitis media: a review. Int J PediatrOtorhinolaryngol. 2006; 70(1):1-1.

2. Y Robin. Complications of suppurative otitis media. Disease of ears by Harold Ludman. $6^{\text {th }}$ Ed. 29 (398399).

3. Mostafa BE, El Fiky LM, El Sharnouby MM. Complications of suppurative otitis media: still a problem in the 21st century.ORL J OtorhinolaryngolRelat Spec. 2009; 71(2):87-92.

4. Paul CA, Kumar ARaut VV, Garhnam A, Kumar N. Pseudomonas cervical Osteomyelitis with retropharyngeal abscess: an unusual complication of otitis media.J Laryngol Otol. 2005; 119(10):816-8.

5. Leskinen $\mathrm{K}$, Jero $\mathrm{J}$. Complications of acute otitis media in children in southern Finland.Int $\mathrm{J}$ PediatrOtorhinolaryngol. 2004; 68(3):317-24.

6. Seven $H$, Coskun BU, Calis $A B$, Sayin I, Turgut S.Intracranial abscesses associated with chronic suppurative otitis media. Eur Arch Otorhinolaryngol. 2005; 262(10):847-51.

7. Wojcik K, Dalecka-Sztwiertnia E, Piekarska A, Zboinska J, Wrodycki W, Kuydowicz J. Brain abscess: analysis of prevalence and clinical course.PrzeglEpidemiol. 2006; 60(2):265-71.

8. Hossain MM, Kundu SC, Haque MR, Shamsuzzaman AK, Khan MK, Halder KK. Extracranial complications of chronic suppurative otitis media.Mymensingh Med J. 2006; 15(1):4-9.

9. Liang $X$, Chen $S, \underline{O u} Y$, Zheng $Y$, Ding J, $\underline{X u Y}$, et al. Clinical analysis of chronic suppurative otitis media in adults and children.Lin Chuang Er Bi Yan HouKeZaZhi. 2005; 19(13):594-5.

10. Migirov L, Duvdevani S, Kronenberg J. Otogenic intracranial complications: a review of 28 cases. Acta Otolaryngol. 2005;125(8):819-22.

11. Razzaq AA, Jooma R, Ahmed S. Trans-mastoid approach to otogenic brain abscess.J Pak Med Assoc. 2006; 56(3):132-5.

12. Olatoke F, Ologe FE, Nwawolo CC, Saka MJ. The prevalence of hearing loss among schoolchildren with chronic suppurative otitis media in Nigeria, and its effect on academic performance. Ear Nose Throat $J$. 2008 Dec;87(12):E19.

13. Dubey $S P$, Larawin V , Molumi CP. Intracranial spread of chronic middle ear suppuration. $\underline{A m} \mathrm{~J}$ Otolaryngol. 2010 Mar-Apr;31(2):73-7.

14. Migirov L, Duvdevani S, Kronenberg J.Otogenic intracranial complications: a review of 28 cases. Acta Otolaryngol. 2005; 125(8):819-22.

15. Mostafa BE, El Fiky LM, El Sharnouby MM. Complications of suppurative otitis media: still a problem in the 21st century.ORL J OtorhinolaryngolRelat Spec. 2009; 71(2):87-92.

16. Dubey SP, Larawin V. Complications of chronic suppurative otitis media and their management.Laryngoscope. 2007; 117(2):264-7.

17. PenidoNde O, Borin A, Iha LC, Suguri VM, et al. Intracranial complications of otitis media: 15 years of experience in 33 patients. Otolaryngol Head Neck Surg. 2005; 132(1):37-42.

18. Zelikovich El. [Computed tomography (CT) of the temporal bone in diagnosis of acquired cholesteatoma of the middle ear]. VestnOtorinolaringol. 2004;(5):28-32. 